\title{
Optoelectronic Vital Capacity Measurement for Restrictive Diseases
}

\author{
Julien Boudarham MSc, Didier Pradon PhD, Hélène Prigent MD PhD, Isabelle Vaugier, \\ Frédéric Barbot, Nadège Letilly, Line Falaize, David Orlikowski MD PhD, \\ Michel Petitjean MD PhD, and Frédéric Lofaso MD PhD
}

\begin{abstract}
OBJECTIVE: To determine whether optoelectronic plethysmography accurately evaluated vital capacity (VC) in patients with respiratory muscle dysfunction of variable severity, including those with paradoxical abdominal movements. METHODS: In 20 subjects, VC was measured in the supine position using both spirometry and optoelectronic plethysmography (6 optoelectronic cameras and 52 reflective markers on the anterior chest wall). RESULTS: Spirometry VC (VC-Spiro) correlated positively with optoelectronic $\mathrm{VC}(\mathrm{VC}-\mathrm{Opto})\left(\mathrm{r}^{2}=0.99, P<.001\right)$, and the regression line was very close to the identity line $(\mathrm{VC}-\mathrm{Opto}[\mathrm{mL}]=-1.202+1.007 \times \mathrm{VC}-$ Spiro $[\mathrm{mL}])$. A Bland-Altman plot showed that the mean difference was $-20 \mathrm{~mL}(95 \% \mathrm{CI}-63 \mathrm{~mL}$ to $24 \mathrm{~mL})$ and the limits of agreement were $163 \mathrm{~mL}(95 \%$ CI $106 \mathrm{~mL}$ to $231 \mathrm{~mL})$ and $-203 \mathrm{~mL}(95 \% \mathrm{CI}-271 \mathrm{~mL}$ to $-146 \mathrm{~mL}$ ). The difference between the 2 values expressed as the percentage of the mean value was $<15 \%$ in all 20 subjects, $<10 \%$ in $17(85 \%)$ subjects, and $<5 \%$ in $11(55 \%)$ subjects. The difference, expressed as the percentage of the mean value, was unrelated to the contribution of abdominal motion to $\mathrm{VC}(\mathrm{r}=\mathbf{0 . 0 2}$ and $P=.94)$, but was significantly related to body mass index $(\mathrm{r}=\mathbf{0 . 5 3}, P=.02)$. CONCLUSIONS: Optoelectronic plethysmography is accurate and suitable for VC measurement in patients with various degrees of respiratory failure, including those with paradoxical abdominal movements. This noninvasive method may be an attractive alternative for accurately measuring VC in the event of air leakage (through the mouth or tracheostomy) or when patients are unable to breathe with the dead space added by the spirometer. Key words: vital capacity; optoelectronic plethysmography; respiratory failure; neuromuscular; spirometry; pulmonary function. [Respir Care 2013;58(4):633-638. (C) 2013 Daedalus Enterprises]
\end{abstract}

\section{Introduction}

One of the best tools for evaluating severe respiratory failure in patients with neuromuscular dysfunction is vital capacity (VC) measurement. ${ }^{1}$ Obstacles to accurate spirometry measurements of $\mathrm{VC}$ in severe patients include mouth leaks due to upper airway muscle dysfunction and

\footnotetext{
The authors are affiliated with Services de Physiologie-Explorations Fonctionnelles, Plateforme d'Analyse du Mouvement, et Centre d'Innovations Technologiques, Unité Mixte de Recherche 805, Hôpital Raymond Poincaré, Assistance Publique Hôpitaux de Paris, Garches, France, with the exception of Dr Petitjean, who is affiliated with Centre de Recherche Sur le Sport et le Mouvement, Université Paris Ouest Nanterre La Défense, Nanterre; et Centre Hospitalier Universitaire d'Amiens, Amiens, France. Dr Lofaso is also affiliated with Institut National de la Santé et de la Recherche Médicale 855, Créteil, France.
}

The authors have disclosed no conflicts of interest. leaks around an uncuffed tracheostomy tube. ${ }^{2-4}$ Furthermore, severely affected patients (best $\mathrm{VC}<5 \%$ ) may be unable to breathe with the dead space added by the spirometer. Optoelectronic plethysmography (OEP) relies on a motion analysis system tracking the movements of reflective markers placed on the chest wall. OEP is a reliable and accurate method of noninvasive evaluation of pulmonary ventilation and the kinematics of the various thoraco-

\footnotetext{
Correspondence: Frédéric Lofaso MD PhD, Services de PhysiologieExplorations Fonctionnelles, Réanimation Médicale, Rééducation Fonctionnelle et Centre d'Investigation Clinique et d'Innovation Technologique, Institut National de la Santé et de la Recherche Médicale Unit 805, Hôpital Raymond Poincaré, 92380 Garches, France. E-mail: f.lofaso@rpc.aphp.fr.
}

DOI: $10.4187 /$ respcare. 01916 
abdominal compartments. OEP measurement of $\mathrm{VC}$ has been validated in 2 normal volunteers. ${ }^{5}$ More specifically, OEP has been used to evaluate compartmental volume changes in the respiration of neuromuscular patients ${ }^{6}$ and in ICU patients receiving mechanical ventilation. ${ }^{7}$ However, OEP has not been specifically validated for VC assessment in a population with severe respiratory dysfunction.

The aim of this study was to validate $\mathrm{VC}$ measurement by OEP using conventional spirometry as the reference standard in a population without air leaks but with various degrees of respiratory muscle dysfunction, in order to know if this method may hold promise for $\mathrm{VC}$ measurement in severe restrictive diseases, especially in patients exhibiting difficulties in performing spirometry, as is often the case for patients in the intensive care setting.

\section{Methods}

From January 2011 to May 2012, the pulmonary function laboratory and the motion analysis laboratory of our hospital worked together to investigate neuromuscular patients referred for respiratory evaluation from the intensive care department of the Raymond Poincaré Teaching Hospital, Garches, France. The local ethics committee approved the study and all subjects gave their informed consent, according to the French law.

Chest wall kinematics and spirometry were recorded simultaneously, with the subjects in the supine position. Supine VC has major clinical importance in patients with advanced restrictive disease. Furthermore, the supine position facilitates paradoxical abdominal movements related to diaphragmatic dysfunction. ${ }^{8}$ Thus, using the supine position allowed us to evaluate OEP under the worst conditions during respiratory failure.

Chest wall kinematics was recorded using a motion analysis system (Motion Analysis, Santa Rosa, California) consisting of 6 optoelectronic cameras and 52 reflective markers placed on the chest wall (Fig. 1), according to the biomechanics model of Cala et al. ${ }^{5}$ Ward et $\mathrm{al}^{9}$ suggested separating the chest wall into 3 compartments: the upper rib cage apposed to the lungs, the lower rib cage apposed to the diaphragm, and the abdomen. Based on this compartmentalization, Cala et $\mathrm{al}^{5}$ developed a biomechanical model simplifying the thorax and abdomen according to a set of anatomical landmarks. This model defines the geometry of the upper and lower thorax and of the abdomen, and can be used for a dynamic evaluation of volume changes in each of the 3 compartments (upper rib cage, lower rib cage, and abdomen). Reflective markers are placed according to specific anatomical landmarks, in 7 horizontal rows between the clavicles and the anterior superior iliac spines, and in 5 vertical columns. The grid thus formed is used to reconstruct the geometry of the entire chest wall.

\section{QUICK LOOK}

\section{Current knowledge}

Vital capacity is one of the best measurements for evaluating respiratory failure in patients with neuromuscular dysfunction. Obstacles to accurate spirometric measurement of vital capacity in critically ill patients include mouth leak due to upper airway muscle dysfunction, and leak around an uncuffed tracheostomy tube. Optoelectronic plethysmography is a noninvasive method for measuring vital capacity in the face of air leaks or when the patient is unable to tolerate the dead space added by the spirometer.

\section{What this paper contributes to our knowledge}

Optoelectronic plethysmography was accurate for measurement of vital capacity in patients with various degrees of respiratory failure, including those with paradoxical abdominal movements.

The compartment boundaries are lines extending circumferentially around the thorax or abdomen at the following sites:

Upper rib cage: clavicles, and xiphoid process

Lower rib cage: xiphoid process and lower costal margin

Abdomen: lower costal margin and anterior-superior iliac spines

The 3-dimensional coordinates of each reflective marker were recorded. Surface triangulation was performed by drawing lines connecting the reflective markers. The triangulated mesh thus obtained and the 3-dimensional coordinates were then used to compute the movement-induced changes in the volume of the entire chest wall and of each of the 3 compartments (upper rib cage, lower rib cage, and abdomen), based on integration of the area enclosed by the triangles using the Gauss divergence theorem.

A pulmonary function testing system (Vmax 229, SensorMedics, Yorba Linda, California) was used to make the spirometric-static measurements of VC. The pulmonary function test technician checked the spirometer calibration, prepared the subject, instructed and demonstrated the slow VC maneuver to the subject, and coached her/him according to standard guidelines, ${ }^{10}$ while another technician recorded chest wall kinematics. During the slow VC maneuver the subject used a mouth-piece and wore a nose clip. The maneuver was performed in a relaxed manner, except near end-inspiration and end-expiration. The subject exhaled completely to residual volume, then inhaled to 

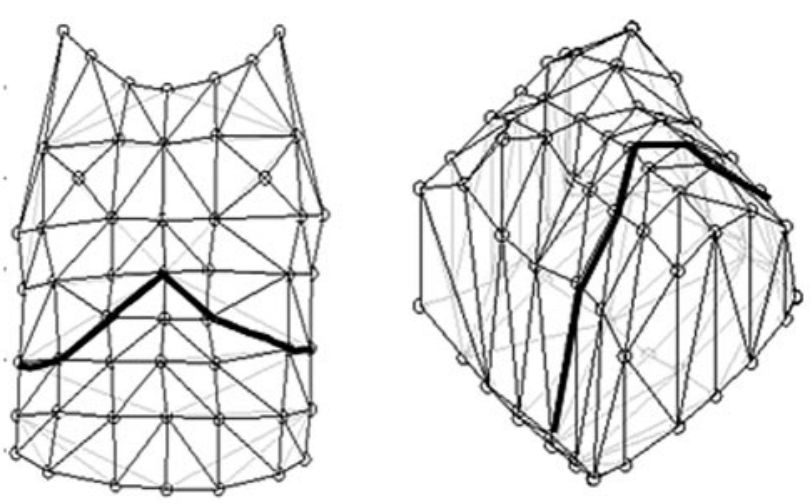

Fig. 1. Markers positioning and geometrical model for optoelectronic plethysmography measurement. The bold line represents the limit between the abdomen and the thorax.

total lung capacity, and finally exhaled to residual volume again. The technician encouraged the subject to reach maximal inhaled and exhaled volumes with a relatively constant flow and observed carefully to ensure that the subject's lips were sealed, the mouth-piece was not obstructed, no leaks occurred, and total lung capacity and residual volume were reached.

Three VC maneuvers were performed. The maneuvers were considered adequate when, using the same measurement method, the difference between the best and worst values was smaller than $0.150 \mathrm{~L}$ (or $<0.1 \mathrm{~L}$ when $\mathrm{VC}$ $<1 \mathrm{~L}) .{ }^{10}$ The best maneuver, which was always the same for each method, was used to compare the 2 techniques. Because the VC measurements by the spirometer and the $\mathrm{VC}$ measurements by OEP were performed simultaneously during the same maneuvers, the $\mathrm{VC}$ difference was due only to instrumental differences or errors.

\section{Statistical Analysis}

All results are expressed as mean $\pm \mathrm{SD}$. For each volume measured, we used linear regression analysis to evaluate the correlation between spirometry and OEP. Agreement between the 2 methods was determined using a BlandAltman plot. ${ }^{11}$

\section{Results}

Among the 20 subjects presented in the Table, 6 had myotonic dystrophy type I, 6 had diaphragmatic dysfunction (neurologic amyotrophy, 5 had Pompe disease (acid maltase deficiency), 1 had spinal muscular atrophy, 1 had mitochondrial myopathy, and 1 had Duchenne muscular dystrophy. VC was $<1 \mathrm{~L}$ in 4 subjects. No air leaks occurred during VC maneuvers using a flanged mouthpiece.

Three subjects with Pompe disease (subjects 7, 8, and 11 ), and 2 with neuralgic amyotrophy (subjects 18 and 19) exhibited paradoxical abdominal movements during supine respiration, and one subject with myotonic dystrophy (subject 1) showed paradoxical motion of the thorax with pulmonary ribcage depression during inspiration, responsible for a decrease in global ribcage volume with an increase in abdominal volume.

As expected, we found a positive correlation between VC measured by spirometry (VC-Spiro) and VC measured using OEP (VC-Opto) $\left(\mathrm{r}^{2}=0.99, P<.001\right)$. The regression line was very close to the identity line:

$$
\text { VC-Opto }(\mathrm{mL})=-1.202+1.007 \times \text { VC-Spiro }(\mathrm{mL})
$$

Figure 2 compares the VC-Opto and VC-Spiro data with a regression graph and a Bland-Altman plot. The mean difference was $-20 \mathrm{~mL}$ (95\% CI $-63 \mathrm{~mL}$ to $24 \mathrm{~mL}$ ) and the limits of agreement were $163 \mathrm{~mL}$ (95\% CI 106-231 mL) and $-203 \mathrm{~mL}(95 \% \mathrm{CI}-271 \mathrm{~mL}$ to $-146 \mathrm{~mL})$. The difference between the 2 values, expressed as the percentage of the mean value, was $<15 \%$ in all 20 subjects, $<10 \%$ in $17(85 \%)$ subjects, and $<5 \%$ in $11(55 \%)$ subjects. The difference between the 2 values, expressed as the percentage of the mean value, was not associated with the contribution of abdominal movements to $\mathrm{VC}(\mathrm{r}=0.02$ and $P=.94)$, but was significantly associated with body mass index (BMI) $(\mathrm{r}=0.53, P=.02)$ (Fig. 3).

\section{Discussion}

In subjects with various degrees of restrictive respiratory disease (from none to very severe), VC-Spiro and VC-Opto showed a strong positive correlation and relatively good agreement. Although the absolute difference between the 2 values seemed larger when $\mathrm{VC}$ was $<2 \mathrm{~L}$ (30 mL vs $20 \mathrm{~mL}$ for all subjects), it did not correlate with the contribution of abdominal movements to VC. Thus, the VC difference was not larger in subjects with paradoxical motion of part of the chest wall or of the abdomen. In contrast, a low or normal BMI was associated with VC-Opto values higher than VC-Spiro values, whereas a high BMI was associated with VC-Opto values lower than VC-Spiro values.

The overestimation of VC-Opto, compared to VC-Spiro, in non-obese subjects can be explained by the intrathoracic blood shift effect.5,7,13 During deep inspiration, the blood volume in the chest compartment tends to increase, because the pleural pressure is more negative at total lung capacity than at functional residual capacity. During deep expiration, chest blood volume tends to decrease, because 
Table. Subjects

\begin{tabular}{|c|c|c|c|c|c|c|c|c|c|}
\hline $\begin{array}{l}\text { Subject } \\
\text { Number }\end{array}$ & Diagnosis & Sex & $\begin{array}{c}\text { Age } \\
(\mathrm{y})\end{array}$ & $\begin{array}{l}\text { Weight } \\
(\mathrm{kg})\end{array}$ & $\begin{array}{l}\text { Height } \\
(\mathrm{cm})^{*}\end{array}$ & $\begin{array}{l}\text { VC-Sup } \\
\text { (mL) }\end{array}$ & $\begin{array}{l}\text { VC-Opto } \\
\text { (mL) }\end{array}$ & $\begin{array}{c}\mathrm{P}_{\operatorname{Imax}} \\
\left(\mathrm{cm} \mathrm{H}_{2} \mathrm{O}\right)\end{array}$ & $\begin{array}{c}\text { NIV } \\
(\mathrm{h} / 24 \mathrm{~h})\end{array}$ \\
\hline 1 & Myotonic dystrophy & $\mathrm{F}$ & 34 & 76 & 155 & 1,480 & 1,350 & 63 & 8 \\
\hline 2 & Myotonic dystrophy & $\mathrm{F}$ & 54 & 67 & 159 & 1,700 & 1,610 & 50 & 7 \\
\hline 3 & Myotonic dystrophy & $\mathrm{F}$ & 46 & 64 & 163 & 2,490 & 2,480 & 61 & ND \\
\hline 4 & Myotonic dystrophy & $\mathrm{F}$ & 43 & 63 & 170 & 2,140 & 2,180 & 34 & ND \\
\hline 5 & Myotonic dystrophy & $\mathrm{F}$ & 36 & 54 & 158 & 1,760 & 1,920 & 43 & 8 \\
\hline 6 & Myotonic dystrophy & M & 40 & 105 & 192 & 4,360 & 4,360 & 65 & ND \\
\hline 7 & Acid maltase deficiency & M & 55 & 90 & 169 & 790 & 690 & 13 & 14 \\
\hline 8 & Acid maltase deficiency & M & 62 & 73 & 168 & 1,190 & 1,250 & 25 & ND \\
\hline 9 & Acid maltase deficiency & M & 65 & 66 & 169 & 3,948 & 3,937 & 16 & 8 \\
\hline 10 & Acid maltase deficiency & M & 36 & 90 & 178 & 3,830 & 3,946 & 84 & ND \\
\hline 11 & Acid maltase deficiency & $\mathrm{F}$ & 53 & 50 & 162 & 570 & 630 & 13 & 23 \\
\hline 12 & Mitochondrial myopathy & $\mathrm{F}$ & 65 & 65 & 165 & 1,580 & 1,800 & 27 & 8 \\
\hline 13 & Duchenne muscular dystrophy & M & 21 & 43 & 187 & 480 & 500 & 5 & 10 \\
\hline 14 & Spinal muscular atrophy & M & 25 & 76 & 185 & 2,530 & 2,429 & 96 & 8 \\
\hline 15 & Neuralgic amyotrophy & M & 56 & 72 & 170 & 3,420 & 3,430 & 89 & ND \\
\hline 16 & Neuralgic amyotrophy & M & 76 & 95 & 182 & 2,660 & 2,740 & 59 & ND \\
\hline 17 & Neuralgic amyotrophy & M & 65 & 70 & 155 & 1,090 & 1,030 & 60 & ND \\
\hline 18 & Neuralgic amyotrophy & M & 37 & 76 & 173 & 1,460 & 1,550 & 29 & 8 \\
\hline 19 & Neuralgic amyotrophy & $\mathrm{F}$ & 80 & 60 & 151 & 1,390 & 1,498 & 26 & 8 \\
\hline 20 & Neuralgic amyotrophy & M & 62 & 82 & 172 & 3,210 & 3,143 & 81 & ND \\
\hline $\begin{array}{l}\text { * The arm-s } \\
\text { VC-Sup }=\mathrm{V} \\
\text { VC-Opto = } \\
\mathrm{P}_{\text {Imax }}=\text { max } \\
\text { NIV = noni } \\
\text { ND = no da }\end{array}$ & $\begin{array}{l}\text { nethod has been used to estimate the non-de } \\
\text { capacity in the supine position by spirometry } \\
\text { capacity in the supine position by optoelect } \\
\text { inspiratory pressure } \\
\text { ve ventilation } \\
\text { ailable }\end{array}$ & $\begin{array}{l}\text { ned body } \\
\text { plethys }\end{array}$ & $\begin{array}{l}\text { ht of sc } \\
\text { aphy }\end{array}$ & subjects. ${ }^{12}$ & & & & & \\
\hline
\end{tabular}
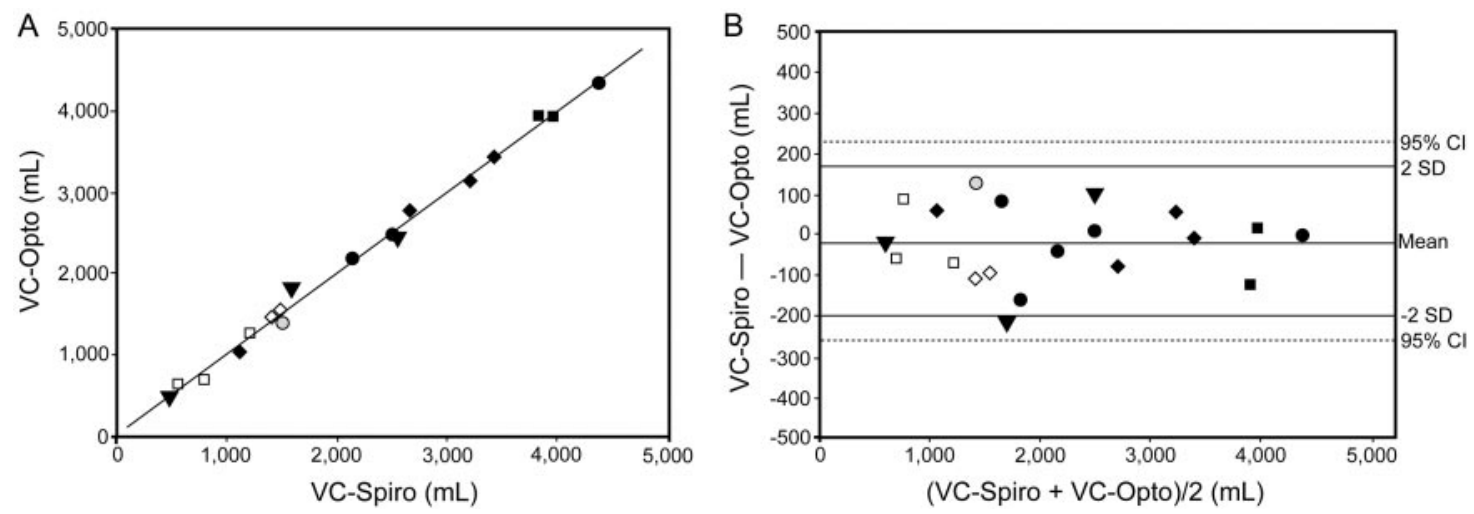

Fig. 2. A: Vital capacity measured using spirometry (VC-Spiro) plotted against VC measured using an optoelectronic system (VC-Opto) and regression line of these 2 parameters. B: Bland-Altman plot of the differences between VC-Spiro and VC-Opto and the mean of VC-Spiro and VC-Opto in 20 subjects. The circles represent subjects with myotonic dystrophic, the squares represent subjects with acid maltase deficiency, the rhombuses represent subjects with neuralgic amyotrophy, and the triangles represent other subjects. The solid symbols indicate subjects without paradoxical ribcage or abdominal motion, the open symbols indicate subjects with paradoxical abdominal motion, and the shaded symbol indicates the subject with paradoxical ribcage motion.

the pleural pressure is higher at residual volume than at functional residual capacity under static conditions. The blood-shift effect tends to increase the changes in chest volume, compared to intrapulmonary gas volume.
In contrast, the underestimation of VC-Opto, compared to VC-Spiro, in subjects with high BMI values can be ascribed to soft tissue artifacts ${ }^{14}$ and faulty positioning of the reflective markers. ${ }^{15}$ Soft tissue artifacts associated 


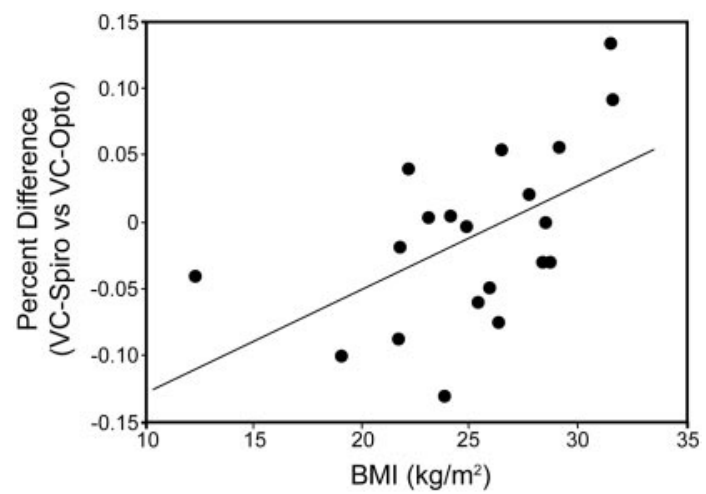

Fig. 3. Body mass index (BMI) versus the percent difference in vital capacity measured via spirometry (VC-Spiro) versus via optoelectronic plethysmography (VC-Opto), calculated as $2 \times$ (VC-Spiro VC-Opto)/(VC-Spiro + VC-Opto).

with the positioning of reflective markers directly on the skin for motion analysis are movements between the skin and underlying bone causing significant measurement error. ${ }^{14}$ Identification via palpation of the subcutaneous anatomical landmarks used to determine marker position is more difficult in patients with high BMI values, mainly because of increased soft tissue thickness. ${ }^{15}$ These results suggest that repeatability of VC-Opto may depend on BMI remaining unchanged between measurements.

Evaluation in the supine position, although clinically useful, is the least favorable situation for OEP measurement of VC. First, posterior chest wall motion cannot be accurately evaluated in the supine position. In the model used in our study, the part of the chest wall in contact with the bed was considered to be immobile throughout the measurements, and virtual markers were used to close the chest compartment. ${ }^{7}$ Second, the supine position facilitates paradoxical abdominal motion in patients with diaphragmatic dysfunction, which may complicate VC measurement, since the decrease in abdominal volume must be subtracted from the increase in chest volume. Despite these drawbacks, OEP provided accurate VC measurements, with $<15 \%$ difference versus spirometry.

Our objective was not to test repeatability, which depends on patients and operators, but to compare OEP to the gold standard during the same maneuver in order to eliminate this variability. As it was not possible to compare OEP to spirometry in intensive care patients for whom spirometry cannot be accurately performed, we performed this comparison in neuromuscular patients who were trained to perform spirometry, and we hypothesized that the results can be extrapolated to the intensive care population, considering that the severity of the respiratory muscle dysfunction of both populations may be comparable. Aliverti et $\mathrm{al}^{7}$ used OEP to study tidal volume and compartmental volume changes in sedated and paralyzed patients with acute lung injury and ARDS receiving continuous me- chanical ventilation, and in patients receiving pressure support ventilation. We hypothesize that the intensive care indications of OEP may include VC measurement in spontaneously breathing patients with respiratory muscle dysfunction.

This study was performed in the motion and gait analysis laboratory of our hospital, which has extensive experience evaluating patients with severe motor impairments and a need for mechanical ventilation. Because this laboratory was close to the pulmonary function laboratory, it was easy to perform OEP and spirometry at the same time. The time needed to position the reflective markers and to calibrate the system was about 30 minutes. Therefore, routine OEP evaluation of a subpopulation of neuromuscular patients in whom accurate spirometry VC measurement is difficult could be considered in a specialized hospital.

\section{Conclusions}

In conclusion, the results obtained in this study suggest that OEP may be an accurate and suitable method for VC measurement in patients having various degrees of respiratory failure, including those with paradoxical abdominal motion, while it seems to perform less accurately in patients with high BMI values. OEP is a noninvasive method that requires no mask or mouthpiece. Thus, OEP may be an attractive alternative for accurately measuring $\mathrm{VC}$ in patients with air leaks (through the mouth or the tracheostomy) and severe respiratory failure in patients unable to breathe with the dead space added by the spirometer.

\section{REFERENCES}

1. American Thoracic Society/European Respiratory Society. ATS/ERS statement on respiratory muscle testing. Am J Respir Crit Care 2002; 166(4):518-624.

2. Bach JR, Alba AS. Tracheostomy ventilation. A study of efficacy with deflated cuffs and cuffless tubes. Chest 1990;97(3):679-683.

3. Prigent H, Samuel C, Louis B, Abinun MF, Zerah-Lancner F, Lejaille $\mathrm{M}$, et al. Comparative effects of two ventilatory modes on speech in tracheostomized patients with neuromuscular disease. Am J Respir Crit Care Med 2003;167(2):114-119.

4. Gonzalez J, Sharshar T, Hart N, Chadda K, Raphael JC, Lofaso F. Air leaks during mechanical ventilation as a cause of persistent hypercapnia in neuromuscular disorders. Intensive Care Med 2003; 29(4):596-602.

5. Cala SJ, Kenyon CM, Ferrigno G, Carnevali P, Aliverti A, Pedotti A, et al. Chest wall and lung volume estimation by optical reflectance motion analysis. J Appl Physiol 1996;81(6):2680-2689.

6. Lo Mauro A, D'Angelo MG, Romei M, Motta F, Colombo D, Comi GP, et al. Abdominal volume contribution to tidal volume as an early indicator of respiratory impairment in Duchenne muscular dystrophy. Eur Respir J 2010;35(5):1118-1125.

7. Aliverti A, Dellaca R, Pelosi P, Chiumello D, Pedotti A, Gattinoni L. Optoelectronic plethysmography in intensive care patients. Am J Respir Crit Care Med 2000;161(5):1546-1552.

8. Wijkstra P, Hazenberg A, Nieuwenhuis J. Vital capacity in lying position: important in Duchenne patients. Eur Respir J 2010;36(5): 1222. 


\section{Optoelectronic Vital Capacity Measurement for Restrictive Diseases}

9. Ward ME, Ward JW, Macklem PT. Analysis of human chest wall motion using a two-compartment rib cage model. J Appl Physiol 1992;72(4):1338-1347.

10. Miller MR, Hankinson J, Brusasco V, Burgos F, Casaburi R, Coates A, et al. Standardisation of spirometry. Eur Respir J 2005;26(2):319-338.

11. Bland JM, Altman DG. Statistical methods for assessing between two methods of clinical measurement. Lancet 1986;1(8476):307-310.

12. Pellegrino R, Viegi G, Brusasco V, Crapo RO, Burgos F, Casaburi $\mathrm{R}$, et al. Interpretative strategies for lung function tests. Eur Respir J 2005;26(5):948-968.
13. Aliverti A, Pedotti A. Opto-electronic plethysmography. Monaldi Arch Chest Dis 2003;59(1):12-16.

14. Leardini A, Chiari L, Della Croce U, Cappozzo A. Human movement analysis using stereophotogrammetry. Part 3. Soft tissue artifact assessment and compensation. Gait Posture 2005;21(2): 212-225.

15. Della Croce U, Leardini A, Chiari L, Cappozzo A. Human movement analysis using stereophotogrammetry. Part 4: assessment of anatomical landmark misplacement and its effects on joint kinematics. Gait Posture 2005;21(2):226-237. 